\title{
Coffee and caffeine intake in relation to symptoms of psychological disorders among adults
}

\author{
Saeedeh Nouri-Majd', Asma Salari-Moghaddam ', Ammar Hassanzadeh Keshteli ${ }^{2,3}$, \\ Hamid Afshar ${ }^{4}$, Ahmad Esmaillzadeh ${ }^{1,5,6, *}$ (⿻) and Peyman Adibi ${ }^{3}$ \\ 'Department of Community Nutrition, School of Nutritional Sciences and Dietetics, Tehran University of Medical \\ Sciences, Tehran 14155-61 17, Iran: ${ }^{2}$ Department of Medicine, University of Alberta, Edmonton, AB, Canada: \\ ${ }^{3}$ Integrative Functional Gastroenterology Research Center, Isfahan University of Medical Sciences, Isfahan, Iran: \\ ${ }^{4}$ Department of Psychiatry, Psychosomatic Research Center, Isfahan University of Medical Sciences, Isfahan, Iran: \\ ${ }^{5}$ Obesity and Eating Habits Research Center, Endocrinology and Metabolism Molecular - Cellular Sciences Institute, \\ Tehran University of Medical Sciences, Tehran, Iran: ${ }^{6}$ Department of Community Nutrition, School of Nutrition and \\ Food Science, Isfahan University of Medical Sciences, Isfahan, Iran
}

Submitted 10 April 2021: Final revision received 26 October 2021: Accepted 20 January 2022: First published online 31 January 2022

\begin{abstract}
Objective: Given that there is an inconsistency in the findings related to the relationship between coffee and caffeine consumption and symptoms of psychological disorders, we performed a cross-sectional analysis to examine the association between coffee and caffeine intake and symptoms of psychological disorders among adults.

Design: In this cross-sectional study, 3362 participants were included. We assessed the coffee and caffeine intakes using a self-completed FFQ. Symptoms of depression, anxiety and psychological distress were assessed using Hospital Anxiety and Depression Scale and General Health Questionnaire screening tools.

Setting: Fifty different healthcare centres located in the province of Isfahan, Iran. Participants: This study was performed on 3362 Iranian general adults working in healthcare centres.

Results: The mean age of participants in this study was $36 \cdot 2 \pm 7 \cdot 8$ years. After controlling for potential confounders, individuals who consumed coffee weekly or more had a significantly lower odds of symptoms of depression (OR 0.67; $95 \%$ CI (0.46, 0.96)) and symptoms of anxiety (OR 0.57; $95 \%$ CI (0.34, 0.95)) compared with those who did not consume coffee. However, no significant association was found between coffee intake and symptoms of psychological distress (OR 0.98; $95 \%$ CI $(0 \cdot 68,1 \cdot 42))$. No significant relationship was found between caffeine intake and odds of symptoms of depression (OR 0.94; $95 \%$ CI $(0 \cdot 75,1 \cdot 16)$ ), symptoms of anxiety (OR 0.90; $95 \%$ CI $(0.67,1.20))$ and symptoms of psychological distress (OR $1 \cdot 13 ; 95 \%$ CI $(0.89,1.42))$.

Conclusion: Compared with lack of coffee intake, weekly or more coffee consumption might be correlated with symptoms of depression and anxiety.
\end{abstract}

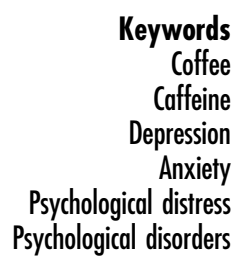

Coffee

Caffeine

epression

Anxiety

Psychological disorders
The increasing trend of mental health disorders in the world has gained great attention ${ }^{(1)}$. Depression and anxiety are the most common psychological disorders in the world that are associated with disability and comorbidity ${ }^{(2)}$. In Iran, the prevalence of mental disorders has been reported at approximately $23 \%{ }^{(3)}$.

Diet has long been associated with mental health. Coffee is a common drink in most parts of the world ${ }^{(4)}$. Evidence for the association between coffee and caffeine intake odds of psychological disorders is limited ${ }^{(5)}$. Some previous studies have examined this association; however, their findings remain inconsistent ${ }^{(6,7)}$. Most studies have found an inverse association between coffee and caffeine intake and risk of mental disorders ${ }^{(8-11)}$. This was also confirmed by a cohort study, within which a linear inverse association between coffee consumption and risk of depression symptoms was reported ${ }^{(12)}$. However, some studies reached no clear association of coffee or caffeine 
intake with depression and anxiety ${ }^{(13,14)}$. Some others have even reported an increased risk of depression by coffee or caffeine consumption $^{(15,16)}$.

Most studies on the association between coffee and caffeine intake and mental health come from Western countries and little information is available from developing countries. Given the nutrition transition in developing countries, changing the pattern of drinking from tea consumption to coffee consumption, along with the high prevalence of depression and anxiety in these countries, assessment of the contribution of coffee and caffeine intake to these conditions is of high importance. It must also be kept in mind that most studies on these relationships did not adjust for many potential confounders that might affect mental health, especially for dietary intakes that can confound the association between coffee and caffeine intake and symptoms of psychological disorders. To our knowledge, no study have been conducted on the association between coffee and caffeine consumption and odds of symptoms of psychological disorders in the general population in the Middle East. Therefore, this study aimed to investigate the association between coffee and caffeine intake and odds of symptoms of psychological disorders including anxiety, depression and psychological distress in the Iranian adult population.

\section{Methods and materials}

\section{Participants}

This study was based on a comprehensive cross-sectional study, named Study on the Epidemiology of Psychological, Alimentary Health and Nutrition (SEPAHAN), in fifty different medical centres throughout Isfahan province, which was affiliated to Isfahan University of Medical Sciences (IUMS). Detailed information about the SEPAHAN project has been published elsewhere ${ }^{(17)}$. Data for this study were collected in two main phases between April 2010 and May 2010. A total of 4763 people completed the questionnaires in both phases. In this study, people who had a total daily energy intake of less than 800 or more than $4200 \mathrm{~kJ} / \mathrm{d}$ were excluded $^{(18)}$, as well as those who completed the questionnaire incompletely and did not have some demographic, anthropometric, dietary or psychological information. Therefore, 3362 participants were included in the analysis of this study, who had complete information about dietary intakes and psychological characteristics. The participant's flowchart for this study has been published in previous articles ${ }^{(19)}$. Written consent forms were given to participants and all of them submitted the form.

\section{Assessment of dietary intake}

In this study, all dietary information was gathered through the use of a Willett-format 106-item semi-quantitative FFQ (DS-FFQ). The investigators of the SEPAHAN study had developed this questionnaire specifically for Iranian adults $^{(20)}$. In this questionnaire, there were five categories of dishes and foods: (1) fruits and vegetables (twentytwo items); (2) mixed dishes (canned or cooked, twentynine items); (3) dairy products (butter, dairies and cream, nine items); (4) grains (cakes, potato, biscuits and different types of bread, ten items) and (5) beverages and miscellaneous food items (including beverages, sweets, desserts, fast foods and nuts, thirty-six items). To calculate the amounts of foods consumed, the booklet of 'household measures' was used ${ }^{(21)}$.

Validation of the questionnaire was examined in a study on 200 randomly selected people. These subjects were requested to fill the questionnaire twice, at the beginning of the study and 6 months later. Three detailed dietary records were also completed by subjects. Comparison of data from the questionnaire and the average of food diaries revealed that the questionnaire works well to estimate long-term dietary intakes ${ }^{(20)}$.

\section{Calculation of coffee and caffeine intake}

Coffee consumption was assessed based on the average number of coffee cups that participants typically consumed in the previous year. Participants could choose from one of the following frequency response categories: 'never or more than 1 cup/month', '1-3 cups/month', ' 1 cup/week', '2-4 cups/week', '5-6 cups/week', '1 cups/d', '2-3 cups/d', ' $4-5$ cups/d' and ' 6 cups or more in a day'. Coffee is not consumed regularly by most people in Iran and is not a common beverage, so we put people in the categories of none, monthly (1-3 cups/month), weekly or more (1-6 cups/week, 1-more than 6 cups/d) based on coffee consumption. Total caffeine intake was estimated by summing up the caffeine that participants took from all caffeine-containing foods and beverages (types of chocolate, cocoa, tea, soft drink and coffee). For each cup of coffee intake in the current study, we considered the caffeine levels as $96 \mathrm{mg}$, as mentioned in the USDA food table ${ }^{(22)}$. Participants were categorised into tertiles based on their caffeine intake $(<57.4 \mathrm{mg} / \mathrm{d}, \quad 57.4-103.4 \mathrm{mg} / \mathrm{d}$ and $\geq 103.5 \mathrm{mg} / \mathrm{d}$ ).

\section{Assessment of psychological profile}

In this study, the Iranian version of the Hospital Anxiety and Depression Scale (HADS) was used to screen for symptoms of anxiety and depression ${ }^{(23)}$. HADS could be a concise and useful questionnaire to evaluate symptoms of psychological disorders and the symptom severity of depression and anxiety disorders. Although the name of this questionnaire seems to be a hospital-based questionnaire, this questionnaire is designed to screen symptoms of depression and anxiety in normal populations and earlier studies have also used this questionnaire for similar purposes. There are published validation studies of this questionnaire that examined its validity and reliability among both healthy and 
diseased populations ${ }^{(23,24)}$. The HADS contains two subscales: anxiety and depression and includes fourteen items. Each item consists of a four-point scale; with increasing scores, the level of anxiety and depressive symptoms also increases and 21 is the maximum score for anxiety and depression. In the current study, people with scores of 0-7 were considered 'normal' and people with scores of 8 or more on both scales were considered as psychological disorders. The convergent validation of translated version of the HADS questionnaire was examined in 167 Iranian adults using the correlation of each item with its hypothesised scale. Pearson's correlation coefficients varied from 0.47 to $0.83(P<0.001)$ for anxiety subscale and from 0.48 to $0.86(P<0.001)$ for the depression subscale, indicating that the questionnaire provides relatively valid measures of psychological health ${ }^{(25)}$. In this study, we used a valid Iranian version of the General Health Questionnaire (GHQ) with twelve items to assess psychological distress $^{(26)}$. At GHQ-12, participants are asked whether they have recently experienced certain symptoms of psychological distress or have changed their behaviour. So, this questionnaire is a short and easy tool for measuring current and primary mental health. In this questionnaire, for each item, there is a four-point scale including much more than usual, rather more than usual, no more than usual or less than usual. There are two common methods for scoring including bimodal (0-0-1-1) and Likert (0-1-2-3), which give a total score of 12 or 36 , respectively. The bimodal scoring method was used in this study. In this study, we defined a score of 4 or more as psychological distress ${ }^{(27)}$. The convergent validity of GHQ-12 was examined in 748 Iranian young people. Significant inverse correlation was seen between the GHQ-12 and global quality of life scores $(r=-0.56, P<0 \cdot 001)^{(26)}$.

\section{Assessment of other variables}

Required information on other variables including sex, age, the existence of a chronic condition (asthma, diabetes, colitis, cancers, stroke, heart failure and myocardial infarction), education, marital status, antidepressant use, smoking status and supplements use (minerals, Fe, Ca and vitamins) obtained through demographic and medical history questionnaires. The General Physical Activity Questionnaire (GPPAQ) was used to assess participants' physical activity levels ${ }^{(28)}$. In this study, participants were classified into two groups: physically inactive $(<1 \mathrm{~h} /$ week $)$ and physically active $(\geq 1 \mathrm{~h} /$ week). The self-report questionnaire was used to collect anthropometric data of participants including height, waist circumference and weight. The validity of self-reported waist circumference, height and weight were examined in a pilot study on 200 participants from the same population. A comparison was made between the self-reported values of anthropometric indices and the measured values in the validation study. The correlation coefficients for self-reported weight, height and waist circumference $v$. corresponding measured values were $0.95 \quad(P<0.001), \quad 0.83 \quad(P<0.001)$ and 0.60 $(P<0.001)$, respectively. BMI was calculated by dividing weight $(\mathrm{kg})$ by height $\left(\mathrm{m}^{2}\right)$. The correlation coefficient for computed BMI from self-reported values and the one from measured values was $0.70(P<0.001)^{(29)}$.

\section{Statistical analysis}

General characteristics of study participants across categories of coffee and caffeine intake were expressed as means and standard deviations for continuous variables and percentages for categorical variables. Dietary intakes of study participants across categories of coffee and caffeine intake were compared using ANOVA. To estimate the OR and $95 \%$ CI for the presence of symptoms of psychological disorders in crude and multivariable-adjusted models, binary logistic regression was used. In these analyses, total energy intake (continuous), age (continuous) and sex (female/ male) were controlled in the first model. Further adjustments were made for education (university graduate or diploma/under-diploma), presence of a chronic condition (no/yes), vitamin supplements use (no/yes), smoking status (current smokers, non-smoker and former smokers), antidepressant use (no/yes), physical activity ( $\geq 1 \mathrm{~h} /$ week/ $<1 \mathrm{~h} /$ week) and marital status (married/single) were controlled for in the second model. Additional adjustments for $n$-3, dietary fibre intake (continuous), B vitamins and tryptophan (all as continuous) were done in the third model. BMI (as kg/ $\mathrm{m}^{2}$ ) was controlled for in the last model. $P_{\text {for trend }}$ was determined by considering categories of coffee and caffeine intake as ordinal variables in the logistic regression analysis.

\section{Results}

In the whole population, the prevalence of symptoms of depression, psychological distress and anxiety were $28 \%$ ( $n$ 943), 22.6\% ( $n$ 760) and $13.3 \%$ ( $n$ 448), respectively.

General characteristics of study participants across categories of coffee and caffeine intake are shown in Table 1. Compared with those who did not consume coffee, those who consumed coffee weekly or more were more likely to be vitamin supplements use $(P<0.001)$, physically active ( $P=0.01)$, current smokers $(P=0.02)$, university graduated $(P<0.001)$ and less likely to have a chronic condition $(P=0.01)$. No other significant differences were seen in terms of other variables. Compared with those in the bottom tertile of caffeine intake, participants in the top tertile of caffeine intake were older $(P<0.001)$, had higher BMI $(P=0.05)$ and were more likely to be university graduates $(P=0 \cdot 01)$. No significant differences were observed in terms of other variables across tertiles of caffeine intake.

Dietary intakes of study participants across categories of coffee and caffeine intake are provided in Table 2. 
Table 1 General characteristics of study participants across categories of coffee and caffeine intake*

\begin{tabular}{|c|c|c|c|c|c|c|c|c|}
\hline & \multicolumn{3}{|c|}{ Coffee intake } & \multirow[b]{3}{*}{$P$-value $†$} & \multicolumn{3}{|c|}{ Caffeine intake } & \multirow[b]{3}{*}{$P$-value } \\
\hline & \multirow{2}{*}{$\frac{\text { None }}{\%}$} & \multirow{2}{*}{$\frac{\text { Monthly }}{\%}$} & \multirow{2}{*}{$\frac{\begin{array}{c}\text { Weekly or } \\
\text { more }\end{array}}{\%}$} & & \multirow{2}{*}{$\frac{\begin{array}{c}\mathrm{T}_{1}(<57.4 \\
\mathrm{mg} / \mathrm{d})\end{array}}{\%}$} & \multirow{2}{*}{$\begin{array}{c}\mathrm{T}_{2}(57.4- \\
103.4 \mathrm{mg} / \mathrm{d}) \\
\%\end{array}$} & \multirow{2}{*}{$\begin{array}{c}\begin{array}{c}T_{3}(\geq 103.5 \\
\mathrm{mg} / \mathrm{d})\end{array} \\
\%\end{array}$} & \\
\hline & & & & & & & & \\
\hline Total sample ( $n$ 3362) & $n 2584$ & $n 491$ & $n 287$ & & $n 1120$ & $n 1121$ & $n 1121$ & \\
\hline \multicolumn{9}{|l|}{ Age (years) } \\
\hline Mean & $36 \cdot 02$ & 36.51 & 35.53 & 0.26 & 35.66 & $36 \cdot 03$ & $37 \cdot 18$ & $<0.001$ \\
\hline SD & $7 \cdot 6$ & $8 \cdot 3$ & $7 \cdot 2$ & & $8 \cdot 2$ & $7 \cdot 6$ & $7 \cdot 6$ & \\
\hline \multicolumn{9}{|l|}{ BMI $\left(\mathrm{kg} / \mathrm{m}^{2}\right)$} \\
\hline Mean & $24 \cdot 87$ & 24.59 & $24 \cdot 75$ & 0.32 & $24 \cdot 66$ & $24 \cdot 85$ & $25 \cdot 19$ & 0.05 \\
\hline SD & $3 \cdot 8$ & $3 \cdot 7$ & 3.4 & & $3 \cdot 7$ & $3 \cdot 8$ & $3 \cdot 8$ & \\
\hline Female & $58 \cdot 8$ & $57 \cdot 6$ & 64.8 & 0.11 & $57 \cdot 1$ & $61 \cdot 6$ & $56 \cdot 1$ & 0.21 \\
\hline Married & $82 \cdot 0$ & 78.7 & 79.2 & 0.15 & $80 \cdot 8$ & $82 \cdot 4$ & $81 \cdot 8$ & 0.60 \\
\hline Antidepressant use & $5 \cdot 7$ & 4.9 & $4 \cdot \overline{2}$ & 0.46 & $5 \cdot 0$ & $6 \cdot 3$ & 5.4 & 0.36 \\
\hline Vitamin supplements use & 28.4 & $32 \cdot 8$ & 39.0 & $<0.001$ & 29.8 & 29.9 & $30 \cdot 3$ & 0.96 \\
\hline Current smokers & $12 \cdot 2$ & $15 \cdot 3$ & $16 \cdot 7$ & 0.02 & $12 \cdot 1$ & $13 \cdot 6$ & $15 \cdot 8$ & 0.36 \\
\hline $\begin{array}{l}\text { Physically active } \\
\text { ( } \geq 1 \mathrm{~h} / \text { week) }\end{array}$ & $12 \cdot 0$ & $16 \cdot 9$ & $12 \cdot 5$ & 0.01 & $12 \cdot 9$ & 11.9 & $14 \cdot 7$ & 1.31 \\
\hline $\begin{array}{l}\text { Education (university } \\
\text { graduate) }\end{array}$ & $61 \cdot 2$ & $68 \cdot 8$ & $75 \cdot 6$ & $<0.001$ & $58 \cdot 8$ & $62 \cdot 4$ & $64 \cdot 5$ & 0.01 \\
\hline $\begin{array}{l}\text { Existence of a chronic } \\
\text { condition }\end{array}$ & 4.9 & $2 \cdot 0$ & 4.5 & 0.01 & $5 \cdot 2$ & 3.9 & $4 \cdot 8$ & 0.34 \\
\hline
\end{tabular}

*All values are mean and standard deviation unless indicated.

†ANOVA for continuous variables and chi-squared test for categorical variables.

Participants who consumed coffee weekly or more had higher intakes of protein, carbohydrate, fat, energy, dietary fibre, vitamin $\mathrm{B}_{12}$, vitamin $\mathrm{B}_{6}$, vitamin $\mathrm{B}_{5}$, vitamin $\mathrm{B}_{3}$, vitamin $\mathrm{B}_{2}, \mathrm{Fe}, \mathrm{Zn}$, tryptophan $(P<0.001)$ and folate $(P=0.02)$ compared with those who did not consume coffee. Participants in the top tertile of caffeine intake had lower intakes of protein, carbohydrate, fat, energy, group B vitamins, Fe, $\mathrm{Ca}, \mathrm{Zn}$ and tryptophan $(P<0.001)$ than those in the bottom tertile.

Crude and multivariable-adjusted OR and 95\% CI for symptoms of psychological disorders across categories of coffee and caffeine intake are present in Table 3. In the fully adjusted model, individuals who consumed coffee weekly or more had a lower odds of symptoms of depression (OR 0.67; $95 \% \mathrm{CI}(0.46,0.96))$ and symptoms of anxiety (OR 0.57; $95 \%$ CI $(0.34,0.95)$ ) than those who did not consume coffee. However, we found no significant relationship between coffee intake and odds of symptoms of psychological distress (OR 0.98; $95 \%$ CI (0.68, 1.42)). When possible confounders were considered, we observed no significant association between caffeine intake and odds of symptoms of depression (OR 0.94; $95 \%$ CI $(0.75,1.16))$, symptoms of anxiety (OR 0.90; $95 \% \mathrm{CI}(0.67,1.20))$ and symptoms of psychological distress (OR 1.13; $95 \%$ CI (0.89, 1.42)).

Gender-stratified crude and multivariable-adjusted OR and $95 \%$ CI for symptoms of psychological disorders across categories of coffee and caffeine intake are indicated in Table 4. We observed no significant relationship between coffee intake and odds of symptoms of depression and anxiety in men. In the crude model, there was a significant positive association between coffee intake and odds of symptoms of psychological distress (OR 1.76 ; $95 \%$ CI $(1.07,2.92))$ in men. This association remained significant after adjustment for energy intake and age (OR 1.91; $95 \%$ CI (1.08, 3.38)). However, this significant relationship disappeared in the fully adjusted model (OR 1.63; $95 \%$ CI $(0 \cdot 82,3 \cdot 23)$ ). We observed no significant association between coffee consumption and odds of symptoms of depression (OR 0.70; $95 \%$ CI $(0.46,1.07)$ ), symptoms of anxiety (OR 0.66; 95\% CI $(0.37,1 \cdot 19))$ and symptoms of psychological distress (OR 0.83; $95 \%$ CI $(0.54,1.29)$ ) in women. In addition, we found no significant association between caffeine intake and odds of symptoms of depression, anxiety and psychological distress in either gender.

BMI-stratified crude and multivariable-adjusted OR and $95 \%$ CI for symptoms of psychological across categories of coffee and caffeine consumption are presented in Table 5. In the crud model, we found that individuals with BMI $<25 \mathrm{~kg} / \mathrm{m}^{2}$ who consumed coffee weekly or more had a lower risk of symptoms of depression (OR 0.67; $95 \%$ CI $(0.45,0.99))$. This significant association remained significant after adjustment for age, sex and energy intake. However, after further adjustment for possible confounders, this relationship became non-significant (OR 0.66 $95 \%$ CI $(0.41,1.06))$. Taking potential confounders into account, we observed a significant inverse association between coffee consumption and symptoms of anxiety among individuals with $\mathrm{BMI}<25 \mathrm{~kg} / \mathrm{m}^{2}$ (OR 0.39; $95 \%$ CI $(0 \cdot 18,0 \cdot 82))$. There was no significant relationship between coffee consumption and symptoms of 
Table 2 Dietary intakes of study participants across categories of coffee and caffeine intake

\begin{tabular}{|c|c|c|c|c|c|c|c|c|c|c|c|c|c|c|}
\hline & \multicolumn{6}{|c|}{ Coffee intake } & \multirow[b]{3}{*}{$P$-value* } & \multicolumn{6}{|c|}{ Caffeine intake } & \multirow[b]{3}{*}{$P$-value } \\
\hline & \multicolumn{2}{|c|}{ None } & \multicolumn{2}{|c|}{ Monthly } & \multicolumn{2}{|c|}{ Weekly or more } & & \multicolumn{2}{|c|}{$\mathrm{T}_{1}(<57.4 \mathrm{mg} / \mathrm{d})$} & \multicolumn{2}{|c|}{$\begin{array}{c}\mathrm{T}_{2}(57.4-103.4 \\
\mathrm{mg} / \mathrm{d}\end{array}$} & \multicolumn{2}{|c|}{$T_{3}(\geq 103.5 \mathrm{mg} / \mathrm{d})$} & \\
\hline & Mean & SD & Mean & SD & Mean & SD & & Mean & SD & Mean & SD & Mean & SD & \\
\hline Energy $(\mathrm{kJ} / \mathrm{d})$ & $2302 \cdot 9$ & 815 & $2545 \cdot 5$ & 771 & 2852 & 725 & $<0.001$ & $2553 \cdot 8$ & 891 & $2202 \cdot 5$ & 687 & $2380 \cdot 2$ & 847 & $<0.001$ \\
\hline Protein $(\mathrm{g} / \mathrm{d})$ & 86.05 & $33 \cdot 1$ & 95.03 & $32 \cdot 1$ & 96.92 & $30 \cdot 6$ & $<0.001$ & $97 \cdot 7$ & $36 \cdot 1$ & $81 \cdot 8$ & $28 \cdot 0$ & $85 \cdot 2$ & $33 \cdot 3$ & $<0.001$ \\
\hline Fat $(g / d)$ & 94.43 & 35.5 & $106 \cdot 95$ & 35 & $121 \cdot 85$ & $34 \cdot 2$ & $<0.001$ & $105 \cdot 23$ & 39 & $91 \cdot 24$ & $31 \cdot 2$ & $99 \cdot 33$ & $38 \cdot 3$ & $<0.001$ \\
\hline Carbohydrate (g/d) & $285 \cdot 3$ & 116 & 309.9 & 107 & $352 \cdot 1$ & 100 & $<0.001$ & 312.5 & 129 & 271.6 & $97 \cdot 8$ & 294.9 & 116 & $<0.001$ \\
\hline Dietary fibre $(\mathrm{g} / \mathrm{d})$ & $22 \cdot 17$ & $9 \cdot 7$ & 23.90 & 8.9 & $24 \cdot 13$ & 8.35 & $<0.001$ & $24 \cdot 67$ & $10 \cdot 6$ & 21.02 & $8 \cdot 24$ & $21 \cdot 84$ & $9 \cdot 39$ & $<0.001$ \\
\hline Vitamin $B_{1}(\mathrm{mg} / \mathrm{d})$ & 1.83 & 0.96 & 1.91 & 0.86 & 1.89 & 0.74 & $0 \cdot 150$ & $2 \cdot 04$ & 1.07 & 1.69 & 0.76 & 1.77 & 0.89 & $<0.001$ \\
\hline Vitamin $B_{2}(\mathrm{mg} / \mathrm{d})$ & $1 \cdot 84$ & 0.75 & 1.96 & 0.68 & 1.96 & 0.64 & $<0.001$ & $2 \cdot 0$ & 0.82 & $1 \cdot 75$ & 0.65 & 1.83 & 0.72 & $<0.001$ \\
\hline Vitamin $B_{3}(\mathrm{mg} / \mathrm{d})$ & $24 \cdot 07$ & $10 \cdot 6$ & $26 \cdot 90$ & $9 \cdot 8$ & $30 \cdot 46$ & $9 \cdot 1$ & $<0.001$ & $27 \cdot 44$ & $11 \cdot 7$ & $22 \cdot 67$ & $8 \cdot 8$ & 24.8 & $10 \cdot 7$ & $<0.001$ \\
\hline Vitamin $B_{5}(\mathrm{mg} / \mathrm{d})$ & $6 \cdot 1$ & $2 \cdot 0$ & $6 \cdot 5$ & 1.9 & $6 \cdot 4$ & 1.8 & $<0.001$ & $6 \cdot 7$ & $2 \cdot 2$ & $5 \cdot 8$ & $1 \cdot 7$ & 5.9 & $2 \cdot 0$ & $<0.001$ \\
\hline Vitamin $B_{6}(\mathrm{mg} / \mathrm{d})$ & 1.94 & 0.73 & $2 \cdot 11$ & 0.71 & $2 \cdot 10$ & 0.69 & $<0.001$ & $2 \cdot 16$ & 0.79 & 1.86 & 0.63 & 1.98 & 0.74 & $<0.001$ \\
\hline Vitamin $B_{12}(\mu \mathrm{g} / \mathrm{d})$ & $2 \cdot 87$ & $1 \cdot 2$ & 3.23 & $1 \cdot 2$ & 3.1 & $1 \cdot 3$ & $<0.001$ & 3.23 & 1.4 & $2 \cdot 8$ & $1 \cdot 1$ & $2 \cdot 8$ & $1 \cdot 3$ & $<0.001$ \\
\hline Folate $(\mu \mathrm{g} / \mathrm{d})$ & $569 \cdot 3$ & 241 & 599 & 225 & $586 \cdot 7$ & 199 & 0.028 & $616 \cdot 3$ & 270 & 533.9 & 194 & 567.7 & 233 & $<0.001$ \\
\hline $\mathrm{Fe}(\mathrm{mg} / \mathrm{d})$ & $17 \cdot 32$ & $7 \cdot 6$ & 18.55 & $7 \cdot 1$ & $18 \cdot 73$ & $6 \cdot 4$ & $<0.001$ & $19 \cdot 36$ & 8.4 & $16 \cdot 24$ & $6 \cdot 1$ & 17.09 & $7 \cdot 4$ & $<0.001$ \\
\hline $\mathrm{Ca}(\mathrm{mg} / \mathrm{d})$ & $974 \cdot 86$ & 566 & $1007 \cdot 4$ & 494 & 989.42 & 427 & 0.467 & $1080 \cdot 9$ & 615 & $912 \cdot 2$ & 480 & $932 \cdot 2$ & 518 & $<0.001$ \\
\hline $\mathrm{Zn}(\mathrm{mg} / \mathrm{d})$ & $10 \cdot 84$ & 3.9 & 11.87 & $3 \cdot 8$ & 11.72 & 3.6 & $<0.001$ & 12.09 & 4.2 & $10 \cdot 36$ & 3.3 & $10 \cdot 71$ & 3.9 & $<0.001$ \\
\hline Tryptophan $(\mu \mathrm{mol} / \mathrm{l})$ & 0.68 & 0.28 & 0.75 & 0.27 & 0.75 & 0.25 & $<0.001$ & 0.76 & 0.31 & 0.65 & 0.23 & 0.67 & 0.27 & $<0.001$ \\
\hline
\end{tabular}


Table 3 Crude and multivariable-adjusted OR and $95 \% \mathrm{Cl}$ for symptoms of psychological disorders across categories of coffee and caffeine intake*

\begin{tabular}{|c|c|c|c|c|c|c|c|c|c|c|c|c|}
\hline & \multicolumn{5}{|c|}{ Coffee intake } & \multirow[b]{3}{*}{$P_{\text {for trend }}$} & \multirow[b]{3}{*}{$\mathrm{T}_{1}(<57.4 \mathrm{mg} / \mathrm{d})$} & \multicolumn{4}{|c|}{ Caffeine intake } & \multirow[b]{3}{*}{$P_{\text {for trend }}$} \\
\hline & \multirow[b]{2}{*}{ None } & \multicolumn{2}{|c|}{ Monthly } & \multicolumn{2}{|c|}{ Weekly or more } & & & \multicolumn{2}{|c|}{$\begin{array}{c}\mathrm{T}_{2}(57.4-103.4 \\
\mathrm{mg} / \mathrm{d})\end{array}$} & \multicolumn{2}{|c|}{$\begin{array}{c}T_{3}(\geq 103.5 \\
\mathrm{mg} / \mathrm{d})\end{array}$} & \\
\hline & & OR & $95 \% \mathrm{Cl}$ & OR & $95 \% \mathrm{Cl}$ & & & OR & $95 \% \mathrm{Cl}$ & OR & $95 \% \mathrm{Cl}$ & \\
\hline \multicolumn{13}{|c|}{ Symptoms of depression } \\
\hline Crude & 1.00 & 0.98 & $0.79,1.22$ & 0.82 & $0.61,1.09$ & 0.23 & 1.00 & 1.06 & $0 \cdot 88,1 \cdot 28$ & 1.02 & $0.84,1 \cdot 22$ & 0.84 \\
\hline Model I† & 1.00 & 0.94 & $0.74,1.19$ & 0.82 & $0.60,1.12$ & 0.22 & 1.00 & 1.00 & $0.82,1.23$ & 1.00 & $0.82,1.22$ & 0.97 \\
\hline Model II & 1.00 & 1.00 & $0.78,1.29$ & 0.87 & $0.63,1.20$ & 0.51 & 1.00 & 1.04 & $0.85,1.29$ & 1.02 & $0.83,1 \cdot 26$ & 0.80 \\
\hline Model III§ & 1.00 & 0.97 & $0.76,1.25$ & 0.69 & $0.48,0.99$ & 0.08 & 1.00 & 1.02 & $0.83,1.26$ & 0.96 & $0.77,1.18$ & 0.71 \\
\hline Model IV\| & 1.00 & 0.97 & $0 \cdot 75,1 \cdot 26$ & 0.67 & $0.46,0.96$ & 0.07 & 1.00 & 1.02 & $0.82,1 \cdot 27$ & 0.94 & $0.75,1 \cdot 16$ & 0.57 \\
\hline \multicolumn{13}{|c|}{ Symptoms of anxiety } \\
\hline Crude & 1.00 & 0.96 & $0.71,1.29$ & 0.82 & $0.55,1.21$ & 0.34 & 1.00 & 0.98 & $0.77,1.25$ & 0.97 & $0.76,1.24$ & 0.82 \\
\hline Model I & 1.00 & 0.93 & $0.67,1.28$ & 0.79 & $0.52,1.21$ & 0.28 & 1.00 & 0.96 & $.074,1.26$ & 0.99 & $0.76,1.29$ & 0.96 \\
\hline Model II & 1.00 & 1.02 & $0.73,1.43$ & $0 \cdot 81$ & $0.52,1.28$ & 0.50 & 1.00 & 1.01 & $0.77,1.33$ & 1.04 & $0.79,1.37$ & 0.75 \\
\hline Model III & 1.00 & 1.00 & $0.71,1.41$ & 0.61 & $0.37,1.01$ & 0.12 & 1.00 & 0.98 & $0.74,1.29$ & 0.94 & $0.71,1.25$ & 0.70 \\
\hline Model IV & 1.00 & 0.98 & $0.69,1.39$ & 0.57 & $0.34,0.95$ & 0.07 & 1.00 & 0.94 & $0.71,1 \cdot 25$ & 0.90 & $0.67,1 \cdot 20$ & 0.48 \\
\hline \multicolumn{13}{|c|}{ Symptoms of psychological distress } \\
\hline Crude & 1.00 & 0.94 & $0.74,1.20$ & 1.04 & $0.78,1.40$ & 0.94 & 1.00 & 1.08 & $0.88,1.32$ & $1 \cdot 12$ & $0.92,1.37$ & 0.24 \\
\hline Model I & 1.00 & 0.94 & $0 \cdot 72,1 \cdot 21$ & 1.05 & $0.77,1.44$ & 0.93 & $1 \cdot 00$ & 1.04 & $0.83,1.29$ & $1 \cdot 17$ & $0.94,1.45$ & $0 \cdot 14$ \\
\hline Model II & 1.00 & 0.98 & $0.75,1.28$ & $1 \cdot 12$ & $0.81,1.55$ & 0.57 & 1.00 & 1.06 & $0.84,1.33$ & 1.26 & $1.01,1.57$ & 0.03 \\
\hline Model III & 1.00 & 0.99 & $0 \cdot 75,1.29$ & 1.05 & $0.73,1.50$ & 0.84 & 1.00 & 1.03 & $0.82,1.29$ & $1 \cdot 18$ & $0.94,1.47$ & 0.14 \\
\hline Model IV & 1.00 & 0.99 & $0.75,1.31$ & 0.98 & $0.68,1.42$ & 0.95 & 1.00 & 0.99 & $0.78,1.25$ & $1 \cdot 13$ & $0.89,1.42$ & 0.28 \\
\hline
\end{tabular}

*Data are OR $(95 \% \mathrm{Cl})$.

†Model I: adjusted for age, sex and energy intake.

¥Model II: additionally, adjusted for marital status, education, antidepressant use, vitamin supplements use, smoking status, physical activity and existence of a chronic condition.

§Model III: additionally, adjusted for dietary fibre, $n-3$, vitamin $B_{1}$, vitamin $B_{2}$, vitamin $B_{3}$, vitamin $B_{5}$, vitamin $B_{6}$, vitamin $B_{12}$, folate and tryptophan.

IIModel IV: additionally, adjusted for BMI.

psychological distress in subjects with BMI $<25 \mathrm{~kg} / \mathrm{m}^{2}$. We found no significant association between coffee intake and symptoms of depression, anxiety and psychological distress among individuals with $\mathrm{BM} \geq 25 \mathrm{~kg} / \mathrm{m}^{2}$. Neither in overweight (BMI $\left.\geq 25 \mathrm{~kg} / \mathrm{m}^{2}\right)$ nor in normal weight (BMI $<25 \mathrm{~kg} / \mathrm{m}^{2}$ ) participants, we failed to find a significant association between caffeine intake and odds of symptoms of depression, anxiety and psychological distress.

\section{Discussion}

In this cross-sectional study, we evaluated the association between coffee and caffeine intake and odds of symptoms of psychological disorders. We found that those who consumed coffee weekly or more had a significant lower chance of symptoms of anxiety and depression. However, we observed no significant relationship between coffee consumption and odds of symptoms of psychological distress. In addition, we observed no significant association between caffeine intake and symptoms of psychological disorders, neither in the whole population nor in the stratified analyses.

Our findings on the link between coffee intake and symptoms of depression were in agreement with previous studies. A prospective cohort study found that coffee, but not caffeine, intake may reduce the risk of depression ${ }^{(30)}$. In addition, findings from a cross-sectional study revealed that coffee consumption was associated with a low prevalence of depressive symptoms; however, there was no significant association between caffeine consumption and prevalence of depressive symptoms ${ }^{(31)}$. Similar findings were also reported from Japan, where individuals who consumed $\geq 2$ cups/d coffee had a lower prevalence of depressive symptoms than those who consumed $<1 \mathrm{cup} / \mathrm{d}$; however, this association was not seen for caffeine intake ${ }^{(32)}$. The protective association of coffee consumption against risk of depression was also seen in a cross-sectional study in Korea ${ }^{(33)}$. In contrast to ours, some studies reached a positive association between coffee consumption and psychological disorders. For instance, in a crosssectional study, female participants who drank $\geq 4$ cups/ $\mathrm{d}$ of any form of coffee had an increased likelihood of having major depression compared with non-coffee drinkers; however, there was no relationship between $<4$ cups/d coffee consumption and odds of depression ${ }^{(15)}$. Another study in Korea revealed that a greater intake of caffeine was positively associated with depression ${ }^{(16)}$. Different findings in different studies might be explained by the discrepancy in subject characteristics and different sample sizes as well as different definitions of depression used. In addition, most studies did not adjust for many potential confounders, especially for dietary intakes that can confound the association between coffee and caffeine intake and symptoms of psychological disorders. Because there was so little information about anxiety, as in a cross-sectional study in the USA found no significant association 
Table 4 Gender-stratified crude and multivariable-adjusted OR and $95 \% \mathrm{Cl}$ for symptoms of psychological disorders across categories of coffee and caffeine intake

\begin{tabular}{|c|c|c|c|c|c|c|c|c|c|c|c|c|}
\hline & \multicolumn{5}{|c|}{ Coffee intake } & \multirow[b]{3}{*}{$P_{\text {for trend }}$} & \multirow[b]{3}{*}{$\mathrm{T}_{1}(<57.4 \mathrm{mg} / \mathrm{d})$} & \multicolumn{4}{|c|}{ Caffeine intake } & \multirow[b]{3}{*}{$P_{\text {for trend }}$} \\
\hline & \multirow[b]{2}{*}{ None } & \multicolumn{2}{|c|}{ Monthly } & \multicolumn{2}{|c|}{ Weekly or more } & & & \multicolumn{2}{|c|}{$\begin{array}{c}\mathrm{T}_{2}(57.4-103.4 \\
\mathrm{mg} / \mathrm{d})\end{array}$} & \multicolumn{2}{|c|}{$\begin{array}{c}\mathrm{T}_{3}(\geq 103 \cdot 5 \\
\mathrm{mg} / \mathrm{d})\end{array}$} & \\
\hline & & OR & $95 \% \mathrm{Cl}$ & OR & $95 \% \mathrm{Cl}$ & & & OR & $95 \% \mathrm{Cl}$ & OR & $95 \% \mathrm{Cl}$ & \\
\hline \multicolumn{13}{|l|}{ Men } \\
\hline \multicolumn{13}{|c|}{ Symptoms of depression } \\
\hline Crude & 1.00 & 1.33 & $0.92,1.91$ & 0.88 & $0.51,1.52$ & 0.68 & 1.00 & 1.21 & $0.88,1.68$ & 1.08 & $0.78,1.48$ & 0.63 \\
\hline Model I & 1.00 & 1.32 & $0.88,1.99$ & 0.88 & $0.47,1.66$ & 0.69 & 1.00 & $1 \cdot 19$ & $0.81,1.73$ & 1.09 & $0.76,1.56$ & 0.64 \\
\hline Model II & 1.00 & 1.36 & $0.89,2.08$ & 0.80 & $0.41,1.52$ & 0.85 & 1.00 & 1.16 & $0.79,1.72$ & 1.02 & $0.70,1.48$ & 0.93 \\
\hline Model III & 1.00 & 1.26 & $0.82,1.95$ & 0.65 & $0.32,1.31$ & 0.68 & 1.00 & 1.12 & $0.76,1.66$ & 0.96 & $0.66,1.40$ & 0.81 \\
\hline Model IV & 1.00 & 1.13 & $0.72,1.77$ & 0.64 & $0.31,1.33$ & 0.50 & 1.00 & $1 \cdot 17$ & $0.78,1.74$ & 0.89 & $0.60,1.33$ & 0.55 \\
\hline \multicolumn{13}{|c|}{ Symptoms of anxiety } \\
\hline Crude & 1.00 & 1.57 & $0.95,2.58$ & 0.92 & $0.41,2.07$ & 0.45 & 1.00 & 0.92 & $0.57,1.49$ & 1.08 & $0.69,1.69$ & 0.71 \\
\hline Model I & 1.00 & $1 \cdot 71$ & $0.98,3.00$ & 0.92 & $0.35,2.40$ & 0.40 & 1.00 & 1.08 & $0.60,1.93$ & 1.45 & $0.86,2.46$ & 0.15 \\
\hline Model II & 1.00 & 1.89 & $1.04,3.41$ & 0.67 & $0.24,1.89$ & 0.67 & 1.00 & 1.08 & $0.59,1.99$ & 1.28 & $0.73,2.24$ & 0.36 \\
\hline Model III & 1.00 & 1.69 & $0.93,3.09$ & 0.42 & $0.13,1.28$ & 0.67 & 1.00 & 1.03 & $0.56,1.90$ & 1.15 & $0.65,2.03$ & 0.60 \\
\hline Model IV & 1.00 & 1.44 & $0.76,2 \cdot 73$ & 0.33 & $0.98,1.17$ & 0.40 & 1.00 & 1.01 & $0.54,1.89$ & 1.09 & $0.60,1.96$ & 0.76 \\
\hline \multicolumn{13}{|c|}{ Symptoms of psychological distress } \\
\hline Crude & 1.00 & 1.46 & $0.99,2 \cdot 15$ & 1.76 & $1.07,2.92$ & 0.007 & 1.00 & $1 \cdot 18$ & $0.82,1 \cdot 70$ & 1.34 & $0.95,1.89$ & 0.08 \\
\hline Model I & 1.00 & 1.47 & $0.96,2.52$ & 1.91 & $1.08,3.38$ & 0.008 & 1.00 & 1.15 & $0.76,1.74$ & 1.44 & $0.99,2 \cdot 11$ & 0.05 \\
\hline Model II & 1.00 & 1.52 & $0.97,2.39$ & 1.70 & $0.93,3.10$ & 0.02 & 1.00 & $1 \cdot 11$ & $0.72,1.72$ & 1.38 & $0.92,2.05$ & 0.10 \\
\hline Model III & 1.00 & 1.49 & $0.94,2.36$ & 1.73 & $0.91,3.29$ & 0.03 & 1.00 & 1.08 & $0.70,1.68$ & $1 \cdot 30$ & $0.87,1.94$ & 0.19 \\
\hline Model IV & 1.00 & 1.39 & $0.86,2.52$ & 1.63 & $0.82,3.23$ & 0.07 & 1.00 & 1.07 & $0.68,1.68$ & $1 \cdot 15$ & $0.75,1.75$ & 0.50 \\
\hline \multicolumn{13}{|c|}{ Women } \\
\hline \multicolumn{13}{|c|}{ Symptoms of depression } \\
\hline Crude & 1.00 & 0.84 & $0.63,1.11$ & 0.74 & $0.52,1.04$ & 0.04 & 1.00 & 0.95 & $0.75,1.19$ & 0.99 & $0.78,1.25$ & 0.97 \\
\hline Model I & 1.00 & 0.79 & $0.59,1.07$ & 0.81 & $0.57,1.17$ & 0.87 & 1.00 & 0.95 & $0.74,1 \cdot 21$ & 0.96 & $0.75,1.23$ & 0.79 \\
\hline Model II & 1.00 & 0.87 & $0.64,1.18$ & 0.92 & $0.64,1.34$ & 0.48 & 1.00 & 1.00 & $0.78,1.29$ & 1.02 & $0.79,1.31$ & 0.86 \\
\hline Model III & 1.00 & 0.85 & $0.63,1.16$ & 0.73 & $0.48,1.11$ & $0 \cdot 10$ & 1.00 & 0.98 & $0.76,1.26$ & 0.93 & $0.72,1.21$ & 0.63 \\
\hline Model IV & 1.00 & 0.91 & $0.66,1.24$ & 0.70 & $0.46,1.07$ & 0.11 & 1.00 & 0.96 & $0.74,1.24$ & 0.94 & $0.72,1.22$ & 0.64 \\
\hline \multicolumn{13}{|c|}{ Symptoms of anxiety } \\
\hline Crude & 1.00 & 0.77 & $0.53,1.16$ & 0.74 & $0.47,1.15$ & 0.08 & 1.00 & 0.95 & $0.71,1.27$ & 0.93 & $0.69,1.25$ & 0.65 \\
\hline Model I & 1.00 & 0.72 & $0.49,1.07$ & 0.78 & $0.48,1.25$ & 0.11 & 1.00 & 0.94 & $0.70,1.27$ & 0.87 & $0.64,1.19$ & 0.39 \\
\hline Model II & 1.00 & 0.79 & $0.52,1.19$ & 0.86 & $0.52,1.43$ & 0.34 & 1.00 & 0.99 & $0.73,1.36$ & 0.95 & $0.68,1.31$ & 0.76 \\
\hline Model III & 1.00 & 0.79 & $0.52,1.21$ & 0.70 & $0.40,1.24$ & 0.14 & 1.00 & 0.94 & $0.69,1.29$ & 0.83 & $0.60,1.16$ & 0.29 \\
\hline Model IV & 1.00 & 0.83 & $0.55,1.27$ & 0.66 & $0.37,1.19$ & 0.13 & 1.00 & 0.90 & $0.65,1.23$ & 0.79 & $0.56,1.11$ & 0.18 \\
\hline \multicolumn{13}{|c|}{ Symptoms of psychological distress } \\
\hline Crude & 1.00 & 0.75 & $0.56,1.02$ & 0.78 & $0.55,1.12$ & 0.06 & 1.00 & 0.99 & $0.77,1.27$ & 1.03 & $0.81,1.33$ & 0.76 \\
\hline Model I & 1.00 & 0.75 & $0.54,1.03$ & 0.85 & $0.59,1.24$ & 0.15 & 1.00 & 1.00 & $0.77,1.29$ & 1.06 & $0.82,1.37$ & 0.63 \\
\hline Model II & 1.00 & 0.78 & $0.56,1.09$ & 0.98 & $0.67,1.44$ & 0.50 & 1.00 & 1.03 & $0.79,1.34$ & $1 \cdot 19$ & $0.91,1.56$ & 0.19 \\
\hline Model III & 1.00 & 0.78 & $0.56,1.10$ & 0.87 & $0.57,1.34$ & 0.27 & 1.00 & 0.98 & $0.75,1.29$ & 1.09 & $0.83,1.44$ & 0.51 \\
\hline Model IV & 1.00 & 0.83 & $0.59,1.17$ & 0.83 & $0.54,1.29$ & 0.26 & 1.00 & 0.93 & $0.71,1.22$ & 1.08 & $0.81,1.43$ & 0.58 \\
\hline
\end{tabular}

Model I: adjusted for age and energy intake.

Model II: additionally, adjusted for marital status, education, antidepressant use, vitamin supplements use, smoking status, physical activity and existence of a chronic condition.

Model III: additionally, adjusted for dietary fibre, $n-3$, vitamin $\mathrm{B}_{1}$, vitamin $\mathrm{B}_{2}$, vitamin $\mathrm{B}_{3}$, vitamin $\mathrm{B}_{5}$, vitamin $\mathrm{B}_{6}$, vitamin $\mathrm{B}_{12}$, folate and tryptophan.

Model IV: additionally, adjusted for BMI.

controversial. Further studies are needed to examine the gender discrepancy in this association.

The reason why we did not observe any significant association between caffeine intake and symptoms of psychological disorders might be explained by the low caffeine intake in the study population. In our study, the average caffeine intake was $98.1 \mathrm{mg} / \mathrm{d}$. However, in previous studies that observed a significant relationship, the average consumption was higher than our study. In a study conducted among university students, the average intake of caffeine was $268 \mathrm{mg} / \mathrm{d}$. Individuals who consumed high caffeine (more than $400 \mathrm{mg} / \mathrm{d}$ ) in that study had an elevated chance for anxiety and psychological distress ${ }^{(36)}$. In the study of psychological disorders in men and women are 
Table 5 BMI-stratified crude and multivariable-adjusted OR and $95 \% \mathrm{Cl}$ for symptoms of psychological disorders across categories of coffee and caffeine intake

\begin{tabular}{|c|c|c|c|c|c|c|c|c|c|c|c|c|}
\hline & \multicolumn{5}{|c|}{ Coffee intake } & \multirow[b]{3}{*}{$P_{\text {for trend }}$} & \multirow[b]{3}{*}{$\mathrm{T}_{1}(<57.4 \mathrm{mg} / \mathrm{d})$} & \multicolumn{4}{|c|}{ Caffeine intake } & \multirow[b]{3}{*}{$P_{\text {for trenc }}$} \\
\hline & \multirow[b]{2}{*}{ None } & \multicolumn{2}{|c|}{ Monthly } & \multicolumn{2}{|c|}{ Weekly or more } & & & \multicolumn{2}{|c|}{$\begin{array}{c}\mathrm{T}_{2}(57.4-103.4 \\
\mathrm{mg} / \mathrm{d})\end{array}$} & \multicolumn{2}{|c|}{$\begin{array}{c}T_{3}(\geq 103.5 \\
\mathrm{mg} / \mathrm{d})\end{array}$} & \\
\hline & & OR & $95 \% \mathrm{Cl}$ & OR & $95 \% \mathrm{Cl}$ & & & OR & $95 \% \mathrm{Cl}$ & OR & $95 \% \mathrm{Cl}$ & \\
\hline \multicolumn{13}{|c|}{$\mathrm{BMI}<25 \mathrm{~kg} / \mathrm{m}^{2}$} \\
\hline \multicolumn{13}{|c|}{ Symptoms of depression } \\
\hline Crude & 1.00 & 0.87 & $0.65,1.18$ & 0.67 & $0.45,0.99$ & 0.04 & 1.00 & 0.87 & $0.67,1.12$ & 0.91 & $0.70,1.17$ & 0.45 \\
\hline Model I & 1.00 & 0.90 & $0.64,1.25$ & 0.65 & $0.42,0.99$ & 0.05 & 1.00 & 0.84 & $0.63,1.10$ & 0.91 & $0.69,1.20$ & 0.51 \\
\hline Model II & 1.00 & 0.95 & $0.67,1.33$ & 0.71 & $0.46,1.10$ & $0 \cdot 16$ & 1.00 & 0.88 & $0.66,1.17$ & 0.92 & $0.68,1.22$ & 0.56 \\
\hline Model III & 1.00 & 0.95 & $0.67,1.35$ & 0.66 & $0.41,1.06$ & 0.13 & 1.00 & 0.85 & $0.64,1.14$ & 0.86 & $0.64,1.16$ & 0.33 \\
\hline \multicolumn{13}{|c|}{ Symptoms of anxiety } \\
\hline Crude & 1.00 & 0.86 & $0.57,1.30$ & 0.52 & $0.28,0.95$ & 0.03 & 1.00 & 0.85 & $0.60,1.20$ & 0.92 & $0.65,1.30$ & 0.62 \\
\hline Model I & 1.00 & 0.85 & $0.54,1.32$ & 0.47 & $0.25,0.92$ & 0.02 & 1.00 & 0.91 & $0.63,1.31$ & 0.98 & $0.67,1.42$ & 0.91 \\
\hline Model II & 1.00 & 0.88 & $0.55,1.41$ & 0.48 & $0.24,0.96$ & 0.04 & 1.00 & 0.97 & $0.66,1.43$ & 1.04 & $0.70,1.54$ & 0.82 \\
\hline Model III & 1.00 & 0.89 & $0.55,1.43$ & 0.39 & $0.18,0.82$ & 0.02 & 1.00 & 0.92 & $0.62,1.35$ & 0.93 & $0.62,1.39$ & 0.73 \\
\hline \multicolumn{13}{|c|}{ Symptoms of psychological distress } \\
\hline Crude & 1.00 & 0.88 & $0.63,1.21$ & 0.83 & $0.56,1.25$ & 0.28 & 1.00 & 1.00 & $0.76,1.32$ & 1.04 & $0.79,1.38$ & 0.73 \\
\hline Model I & 1.00 & 0.93 & $0.65,1.32$ & 0.85 & $0.55,1.31$ & 0.43 & 1.00 & 0.94 & $0.70,1.26$ & 1.04 & $0.77,1.40$ & 0.77 \\
\hline Model II & 1.00 & 0.92 & $0.64,1.34$ & 0.90 & $0.58,1.40$ & 0.58 & 1.00 & 0.96 & $0.71,1.31$ & 1.10 & $0.81,1.49$ & 0.54 \\
\hline Model III & 1.00 & 0.96 & $0.66,1.39$ & 0.95 & $0.59,1.54$ & 0.80 & 1.00 & 0.94 & $0.69,1.28$ & 1.07 & $0.78,1.46$ & 0.67 \\
\hline \multicolumn{13}{|c|}{$\mathrm{BMI} \geq 25 \mathrm{~kg} / \mathrm{m}^{2}$} \\
\hline \multicolumn{13}{|c|}{ Symptoms of depression } \\
\hline Crude & 1.00 & 1.14 & $0.82,1.59$ & 1.01 & $0.66,1.56$ & 0.67 & 1.00 & 1.39 & $1.05,1.85$ & 1.20 & $0.90,1.58$ & 0.23 \\
\hline Model I & 1.00 & 1.03 & $0.71,1.48$ & 1.14 & $0.71,1.83$ & 0.59 & 1.00 & 1.31 & $0.96,1.78$ & 1.19 & $0.88,1.61$ & 0.28 \\
\hline Model II & 1.00 & $1 \cdot 14$ & $0.78,1.67$ & $1 \cdot 18$ & $0.72,1.96$ & 0.37 & 1.00 & 1.32 & $0.96,1.82$ & 1.25 & $0.91,1.71$ & 0.18 \\
\hline Model III & 1.00 & 1.08 & $0.73,1.58$ & 0.83 & $0.47,1.46$ & 0.76 & 1.00 & 1.30 & $0.94,1.80$ & $1 \cdot 16$ & $0.84,1.60$ & 0.37 \\
\hline \multicolumn{13}{|c|}{ Symptoms of anxiet } \\
\hline Crude & 1.00 & 1.05 & $0.68,1.63$ & $1 \cdot 13$ & $0.65,1.95$ & 0.63 & 1.00 & $1 \cdot 11$ & $0.77,1.59$ & 0.94 & $0.66,1.35$ & 0.75 \\
\hline Model I & 1.00 & 0.98 & $0.60,1.59$ & 1.29 & $0.70,2.38$ & 0.51 & 1.00 & 1.01 & $0.68,1.50$ & 0.96 & $0.64,1.42$ & 0.83 \\
\hline Model II & 1.00 & $1 \cdot 16$ & $0.69,1.95$ & 1.33 & $0.69,2.58$ & 0.32 & 1.00 & 1.02 & $0.68,1.55$ & 1.01 & $0.67,1.53$ & 0.94 \\
\hline Model III & 1.00 & 1.13 & $0.67,1.91$ & 0.92 & $0.43,1.96$ & 0.93 & 1.00 & 1.02 & $0.67,1.54$ & 0.92 & $0.60,1.40$ & 0.69 \\
\hline \multicolumn{13}{|c|}{ Symptoms of psychological distress } \\
\hline Crude & 1.00 & 1.05 & $0.73,1.52$ & $1 \cdot 30$ & $0.83,2.03$ & 0.26 & 1.00 & $1 \cdot 16$ & $0.85,1.58$ & 1.22 & $0.90,1.65$ & 0.19 \\
\hline Model I & 1.00 & 0.97 & $0.66,1.44$ & 1.40 & $0.86,2.29$ & 0.28 & 1.00 & $1 \cdot 15$ & $0.82,1.62$ & 1.35 & $0.98,1.88$ & 0.06 \\
\hline Model II & 1.00 & 1.08 & $0.72,1.62$ & 1.50 & $0.90,2.49$ & 0.13 & 1.00 & $1 \cdot 15$ & $0.81,1.64$ & 1.50 & $1.07,2.11$ & 0.01 \\
\hline Model III & 1.00 & 1.05 & $0.69,1.59$ & 1.20 & $0.68,2.13$ & 0.52 & 1.00 & 1.13 & $0.79,1.60$ & 1.35 & $0.96,1.91$ & 0.07 \\
\hline
\end{tabular}

Model I: adjusted for age, sex and energy intake.

Model II: additionally, adjusted for marital status, education, antidepressant use, vitamin supplements use, smoking status, physical activity and existence of a chronic condition.

Model III: additionally, adjusted for dietary fibre, $n-3$, vitamin $B_{1}$, vitamin $B_{2}$, vitamin $B_{3}$, vitamin $B_{5}$, vitamin $B_{6}$, vitamin $B_{12}$, folate and tryptophan.

Lucas 2011, which reported an inverse relationship between caffeine consumption and risk of depression, people in the highest category consumed $\geq 550 \mathrm{mg} / \mathrm{d}^{(8)}$. However, in our study, those in the highest category of caffeine consumed an average of $185.3 \mathrm{mg} / \mathrm{d}$, which was far lower than the previous studies. Therefore, we assumed that the low amount of caffeine intake, which is due to the food culture of Iranians, might justify the lack of finding a significant relationship.

In our study, when we performed gender-stratified analysis, the associations disappeared. This might be explained by the presence of some gender-dependent confounders that we failed to control for them in our analysis. Another point that might provide some reasons for this finding is the number of people with symptoms of psychological disorders that would be low in the gender-stratified analysis, compared to the combined analysis on men and women together. Such a low number of people with the outcome would result in wide CI of OR that would in turn result in a non-significant association.

In BMI-stratified analyses, we found no significant association between caffeine intake and symptoms of psychological disorders. In line with our study, a cross-sectional study reported no significant association between caffeine intake and odds of depression in BMI-stratified analyses ${ }^{(11)}$. In this study, a significant inverse association was observed between coffee consumption and odds of anxiety in subjects with $\mathrm{BMI}<25 \mathrm{~kg} / \mathrm{m}^{2}$. This finding might be explained by the fact that being overweight might mask the favourable association of coffee intake and symptoms of depression and anxiety in obese people due to the elevated inflammation that might be aroused from accumulated body fat.

The mechanisms through which coffee intake might influence psychological health are largely unknown; however, these effects can be attributed to the presence of 
antioxidant substances with potentially beneficial properties, for example, chlorogenic acid, flavonoids, melanoidins and trigonelline in coffee ${ }^{(37,38)}$. In a recent study, chlorogenic acid protects pheochromocytoma (PC12) cells against corticosterone-induced neurotoxicity related to inhibition of autophagy and apoptosis and, in turn, may alleviate depression ${ }^{(39)}$. Neuroprotective, antioxidant, anti-inflammatory and anti-apoptotic properties have also been found in some coffee phenolic acid compounds such as caffeic acid, chlorogenic acid and ferulic acid ${ }^{(40)}$. An animal study found that caffeic acid and caffeine in coffee exhibit anxiolytic and antidepressant effects by protecting inflammatory markers ${ }^{(41)}$. Also, the phenolic acids in coffee cross the blood-brain barrier and are present in the cerebrospinal fluid and could possibly affect brain health ${ }^{(42)}$. In this regard, a recent study showed that a higher intake of dietary phenolic acid was associated with a significant reduction in cognitive status ${ }^{(43)}$.

Some studies have attributed the effects of coffee consumption to its caffeine content ${ }^{(8)}$; however, we failed to find any significant association between caffeine intake and symptoms of depression. This shows that factors other than caffeine might be involved in the protective association of coffee against symptoms of psychological disorders.

Several strengths in this study make the findings interesting. The large sample size of the study and considering a wide range of potential confounders in the statistical analysis are among the strengths of this study. Although, our study has some limitations which must be noted. The cross-sectional design of this study would not allow us to confer a causal relationship between coffee and caffeine intake and symptoms of psychological disorders; therefore, more prospective studies are required to support our results. Furthermore, causality in cross-sectional studies cannot be inferred. Individuals who are anxious or depressed consume more coffee, which is a comfort drink. Such mental disorders might lead to higher consumption of coffee, chocolate, sweets, etc. Although we controlled the analyses for many potential confounders, residual confounding cannot be excluded. Coffee consumption might be affected by the health condition of some participants. In addition, the pattern of consumption of these kinds of comfort foods or drinks is strongly associated with other lifestyle characteristics that might not be captured in our analyses. Moreover, using self-reported questionnaires could be considered as another limitation of this study which might lead to misclassifications of participants in terms of exposure and outcome. Although we used a validated FFQ for the assessment of dietary intakes, the questionnaire was not validated for coffee and caffeine intake. In addition, participants of our study were healthcare workers, which might be health-conscious and have different characteristics than the general population. Moreover, in this study, detailed information about the type of coffee and its concentration was not collected and we did not investigate the association of different types of coffee with symptoms of psychological disorders due to a lack of data. Finally, we considered energy intakes outside the range of $800-4200 \mathrm{~kJ} / \mathrm{d}$ as an exclusion criterion in the whole study population; however, some investigators have used different cut-off points to define energy under- and over-reported among men and women ${ }^{(12)}$. When we used the suggested cut-off point of 500-3500 kJ/d for women, we had to further exclude 187 women. However, our main findings did not differ even with excluding these women from the study.

In conclusion, compared with lack of coffee intake, weekly or more coffee consumption might be correlated with symptoms of depression and anxiety. No significant correlation was observed between coffee intake and symptoms of psychological distress. Caffeine intake was not correlated with symptoms of psychological disorders.

\section{Acknowledgements}

Acknowledgements: The authors thank the participants of SEPAHAN project and authorities of Isfahan University of Medical Sciences for their excellent cooperation. Financial support: This study was financially supported by a grant from National Institute for Medical Research Development (grant no. 996007). Conflict of interest: Authors declare that they have no conflict of interest. Authorship: S.N.-M. is a Master's student at the Department of Community Nutrition, School of Nutritional Sciences and Dietetics, Tehran University of Medical Sciences, Tehran, Iran. She is interested in investigating diet-disease associations. A.S.-M. is a PhD Candidate at the Department of Community Nutrition, School of Nutritional Sciences and Dietetics, Tehran University of Medical Sciences, Tehran, Iran. She is interested in investigating diet-disease associations, especially in the field of mental well-being. A.H.K. is a $\mathrm{PhD}$ Candidate at the Department of Medicine, University of Alberta, Edmonton, Canada. H.A. is a Professor (full) at the Psychosomatic Research Center, Department of Psychiatry, Isfahan University of Medical Sciences, Isfahan, Iran. A.E. is a Professor (full) at the Department of Community Nutrition, School of Nutritional Sciences and Dietetics, Tehran University of Medical Sciences, Tehran, Iran. His research interest is to develop and validate dietary strategies that effectively protect against obesity-associated chronic conditions, including metabolic syndrome, CVD, gastrointestinal disease, psychological disorders and different types of cancer. P.A. is a Professor (full) of Medicine in the field gastroenterology at the Department of Internal Medicine, Isfahan University of Medical Sciences, Isfahan, Iran. Ethics of buman subject participation: This study was conducted according to the guidelines laid down in the Declaration of Helsinki, and all procedures involving research study participants were approved by the Regional Bioethics 
Committee of Isfahan University of Medical Sciences in July 2012. Written informed consent was obtained from all patients.

\section{References}

1. World Health Organization (2018) Mental Health in Primary Care: Illusion or Inclusion? World Health Organization. https://apps.who.int/iris/handle/10665/326298 (accessed March 2021).

2. Stein DJ, Scott KM, de Jonge P et al. (2017) Epidemiology of anxiety disorders: from surveys to nosology and back. Dialogues Clin Neurosci 19, 127-136.

3. Noorbala AA, Bagheri Yazdi SA, Yasamy MT et al. (2004) Mental health survey of the adult population in Iran. BrJ Psychiatry 184, 70-73.

4. Butt MS \& Sultan MT (2011) Coffee and its consumption: benefits and risks. Crit Rev Food Sci Nutr 51, 363-373.

5. Grosso G, Godos J, Galvano F et al. (2017) Coffee, caffeine, and health outcomes: an umbrella review. Annu Rev Nutr 37, 131-156.

6. Grosso G, Micek A, Castellano S et al. (2016) Coffee, tea, caffeine and risk of depression: a systematic review and doseresponse meta-analysis of observational studies. Mol Nutr Food Res 60, 223-234.

7. Wang L, Shen X, Wu Y et al. (2016) Coffee and caffeine consumption and depression: a meta-analysis of observational studies. Aust N Z J Psychiatry 50, 228-242.

8. Lucas M, Mirzaei F, Pan A et al. (2011) Coffee, caffeine, and risk of depression among women. Arch Intern Med 171, 1571-1578.

9. Omagari K, Sakaki M, Tsujimoto Y et al. (2014) Coffee consumption is inversely associated with depressive status in Japanese patients with type 2 diabetes. J Clin Biochem Nutr 55, 135-142.

10. Kim J \& Kim J (2018) Green tea, coffee, and caffeine consumption are inversely associated with self-report lifetime depression in the Korean population. Nutrients 10, 1201.

11. Iranpour S \& Sabour S (2019) Inverse association between caffeine intake and depressive symptoms in US adults: data from national health and nutrition examination survey (NHANES) 2005-2006. Psychiatry Res 271, 732-739.

12. Navarro AM, Abasheva D, Martínez-González MÁ et al. (2018) Coffee consumption and the risk of depression in a middle-aged cohort: the sun project. Nutrients 10,1333.

13. Kwok MK, Leung GM \& Schooling CM (2016) Habitual coffee consumption and risk of type 2 diabetes, ischemic heart disease, depression and Alzheimer's disease: a Mendelian randomization study. Sci Rep 6, 36500.

14. Eaton WW \& McLeod J (1984) Consumption of coffee or tea and symptoms of anxiety. Am J Public Health 74, 66-68.

15. Yu ZM, Parker L \& Dummer TJB (2017) Associations of coffee, diet drinks, and non-nutritive sweetener use with depression among populations in eastern Canada. Sci Rep 7, 6255 .

16. Jin MJ, Yoon CH, Ko HJ et al. (2016) The relationship of caffeine intake with depression, anxiety, stress, and sleep in Korean adolescents. Korean J Fam Med 37, 111-116.

17. Adibi P, Keshteli AH, Esmaillzadeh A et al. (2012) The study on the epidemiology of psychological, alimentary health and nutrition (SEPAHAN): overview of methodology. J Res Med Sci 17, S292-S298.

18. Wang ET, de Koning L \& Kanaya AM (2010) Higher protein intake is associated with diabetes risk in South Asian Indians: the metabolic syndrome and atherosclerosis in South Asians living in America (MASALA) study. $J \mathrm{Am}$ Coll Nutr 29, 130-135.
19. Ebrahimpour-Koujan S, Keshteli AH, Afshar H et al. (2019) Adherence to low carbohydrate diet and prevalence of psychological disorders in adults. Nutr J 18, 1-9.

20. Keshteli AH, Esmaillzadeh A, Rajaie S et al. (2014) A dishbased semi-quantitative food frequency questionnaire for assessment of dietary intakes in epidemiologic studies in Iran: design and development. Int J Prev Med 5, 29.

21. Ghaffarpour M, Houshiar-Rad A \& Kianfar H (1999) The Manual For Household Measures, Cooking Yields Factors and Edible Portion of Foods. Tehran: Nashre Olume Keshavarzy.

22. United States Department of Agriculture (2021) Coffee. https://fdc.nal.usda.gov/fdc-app.html\#/food-details/1104137/ nutrients (accessed February 2021).

23. Montazeri A, Vahdaninia M, Ebrahimi M et al. (2003) The hospital anxiety and depression scale (HADS): translation and validation study of the Iranian version. Health Qual Life Outcomes 1, 1-5.

24. Bocéréan C \& Dupret E (2014) A validation study of the hospital anxiety and depression scale (HADS) in a large sample of French employees. BMC Psychiatry 14, 354.

25. Montazeri A, Vahdaninia M, Ebrahimi M et al. (2003) The hospital anxiety and depression scale (HADS): translation and validation study of the Iranian version. Health Qual Life Outcomes 1, 14.

26. Montazeri A, Harirchi AM, Shariati M et al. (2003) The 12item general health questionnaire (GHQ-12): translation and validation study of the Iranian version. Health Qual Life Outcomes 1, 66.

27. Schmitz N, Kruse J, Heckrath C et al. (1999) Diagnosing mental disorders in primary care: the general health questionnaire (GHQ) and the symptom check list (SCL-90-R) as screening instruments. Soc Psychiatry Psychiatric Epidemiol 34, 360-366.

28. Department of Health (2009) The General Practice Physical Activity Questionnaire. London: Department of Health.

29. Aminianfar A, Saneei P, Nouri M et al. (2021) Validity of selfreported height, weight, body mass index and waist circumference in Iranian adults. Int J Prev Med 12, 75.

30. Ruusunen A, Lehto SM, Tolmunen T et al. (2010) Coffee, tea and caffeine intake and the risk of severe depression in middle-aged Finnish men: the Kuopio ischaemic heart disease risk factor study. Public Health Nutr 13, 1215-1220.

31. Kimura Y, Suga H, Kobayashi S et al. (2019) Intake of coffee associated with decreased depressive symptoms among elderly Japanese women: a multi-center cross-sectional study. J Epidemiol 8, 338-344.

32. Pham NM, Nanri A, Kurotani K et al. (2014) Green tea and coffee consumption is inversely associated with depressive symptoms in a Japanese working population. Public Health Nutr 17, 625-633.

33. Park RJ \& Moon JD (2015) Coffee and depression in Korea: the fifth Korean national health and nutrition examination survey. Eur J Clin Nutr 69, 501-504.

34. Botella P \& Parra A (2003) Coffee increases state anxiety in males but not in females. Hum Psychopharmacol 18, 141-143.

35. Mino Y, Yasuda N, Fujimura T et al. (1990) Caffeine consumption and anxiety and depressive symptomatology among medical students. Arukoru Kenkyuto Yakubutsu Izon 25, 486.

36. Jahrami H, Al-Mutarid M, Penson PE et al. (2020) Intake of caffeine and its association with physical and mental health status among university students in Bahrain. Foods 9, 473 .

37. Godos J, Pluchinotta FR, Marventano S et al. (2014) Coffee components and cardiovascular risk: beneficial and detrimental effects. Int J Food Sci Nutr 65, 925-936.

38. Hritcu L, Ionita R, Postu PA et al. (2017) Antidepressant flavonoids and their relationship with oxidative stress. Oxid Med Cell Longev 2017, 5762172. 
39. Shi X, Zhou N, Cheng J et al. (2019) Chlorogenic acid protects PC12 cells against corticosterone-induced neurotoxicity related to inhibition of autophagy and apoptosis. $B M C$ Pharmacol Toxicol 20, 56.

40. Szwajgier D, Borowiec K \& Pustelniak K (2017) The neuroprotective effects of phenolic acids: molecular mechanism of action. Nutrients 9, 477.

41. Mudgal J, Basu Mallik S, Nampoothiri M et al. (2020) Effect of coffee constituents, caffeine and caffeic acid on anxiety and lipopolysaccharide-induced sickness behavior in mice. $J$ Funct Foods 64, 103638.

42. Grabska-Kobylecka I, Kaczmarek-Bak J, Figlus $\mathrm{M}$ et al. (2020) The presence of caffeic acid in cerebrospinal fluid: evidence that dietary polyphenols can cross the blood-brain barrier in humans. Nutrients 12, 1531.

43. Godos J, Caraci F, Micek A et al. (2021) Dietary phenolic acids and their major food sources are associated with cognitive status in older Italian adults. Antioxidants 10, 700. 